\title{
'Clarity' Begins at Home: An Examination of the Conceptual Underpinnings of the IAASB's Clarity Project
}

\section{Ian Dennis \\ Oxford Brookes University}

This paper examines the IAASB's policy proposals arising out of their review of the drafting conventions in auditing standards that has become known as the Clarity Project. The objectives of the Project and how they changed during its evolution are reviewed. One motivation for the Project was to ensure that auditing standards drafted by the IAASB are 'principles-based'. The failure to adequately consider the meaning of "principlesbased standards' was responsible for a lack of clear focus on what was wanted from the Project. This resulted in two main objectives for the Project. The first was a search for fundamental principles of auditing that was incompletely realized, officially abandoned and subsequently covertly pursued in the revisions made to ISA 200. The second was a desire to promulgate standards that were 'objectives-based' or 'principles-based'. Unfortunately, there was inadequate enquiry into the idea of an objective and the related idea of 'objectives-based' standards. The paper clarifies their nature. It examines the idea of a conceptual framework for auditing and the explanations of objectives and 'objectivesbased' standards that emerged during the evolution of the Project. It considers the ideas objectives in ISAs, requirements and explanatory material in order to throw light on the nature of auditing standards that contain them. The question of whether an important distinction between 'requirements' and 'presumptive requirements' has been lost between the first and the second Exposure Draft is examined. This distinction can be explained and justified in terms of a distinction between different concepts of rules. It is suggested that the Clarity Project was a missed opportunity. The results are uncertain because there was a failure to undertake adequate conceptual enquiry into some of the concepts that directed its development. A start is made in rectifying this omission in the paper.

Key words: Audit objectives, auditing standards, Clarity Project, conceptual framework for auditing, 'principles-based' standards, principles of auditing, audit requirements.

Correspondence to: Dr Ian Dennis, Senior Lecturer in Accounting and Finance, Oxford Brookes University Business School, Wheatley Campus, Wheatley, Oxford OX33 1HX, UK. Email: iddennis@brookes.ac.uk 


\section{SUMMARY}

The paper considers the conceptual underpinnings of the Clarity Project. The Project arose from a review of the drafting conventions used in auditing standards issued by the IAASB. One objective of the Project was to ensure that auditing standards were 'principles-based'. The concept of a 'principles-based' auditing standard was not adequately examined. One understanding of the nature of such standards is that they are 'based on' or 'derived from' a framework of principles of auditing. This conception led the Project to investigate the possibility of constructing a conceptual framework for auditing or 'fundamental principles of auditing'. The development of this part of the project is reviewed. This objective was abandoned for logistical reasons. The nature of this kind of framework is examined. Its purpose and the use of the framework are examined by considering how it is used by standard setters in practical reasoning towards a desire to promulgate auditing standards. The extent to which the desire to construct such a framework re-emerged in the revision of ISA 200 is considered. Another understanding of a 'principles-based' auditing standard is that it is a standard with certain characteristics. These were identified as being a standard that contains an objective. The IAASB's, and its constituents', understanding of the nature of objectives and of 'objectives-based' standards is examined and critiqued. It is suggested that there was inadequate conceptual enquiry into these concepts. The paper examines possible meanings of these concepts as well as the nature of objectives in ISAs, requirements and explanatory material. It is suggested that the Clarity Project constitutes a missed opportunity to consider these meanings carefully and to clarify the nature of auditing standards. Objectives in ISAs sometimes express desires for auditors to undertake procedures and sometimes express requirements. Although a requirement may be understood as a rule, the nature of rules and, in particular, the different kinds of rules that might be included in an auditing standard were not considered very carefully. The paper uses the ideas of Rawls (1955) about different kinds of rules to throw light on the IAASB's conception of rules. It also considers the nature of explanatory material and how it is related to requirements and objectives. The paper concludes that the shortcomings of the Clarity Project result from inadequate conceptual enquiry into the concepts that guided its development.

\section{THE OBJECTIVES OF THE CLARITY PROJECT}

The International Auditing and Assurance Standards Board (IAASB) is an independent standard-setting board within the International Federation of Accountants (IAASB, 2007). Its objective is 'to serve the public interest by setting high-quality auditing and assurance standards and by facilitating the convergence of international and national auditing and assurance standards, thereby enhancing the quality and consistency of practice throughout the world and strengthening public confidence in the global auditing and assurance profession' (IAASB, 2010). To assist in meeting this objective the IAASB embarked on a programme to enhance the clarity of its International Standards on Auditing (ISAs) in 2004. This became known as the Clarity Project and arose from a review of the drafting conventions used in these standards. The new conventions were used to re-draft existing ISAs which are effective for audits of financial statements for periods beginning on or after December 15, 2009. The project began by addressing the narrower issues of whether bold and plain type lettering conveyed the respective authority of the statements with sufficient clarity, whether the language used in standards adequately identified the responsibilities of the professional accountant and whether 'actions expressed in the present tense' constituted obligations or not (IAASB, 2004a, p. 2). Wider issues were also addressed concerning the 'understandability' of standards in the light of 'their increased length' and the question of whether they were unduly complex or rules-based despite the claim that they are 'principles-based' (IAASB, 2004a, p. 27). Respondents were asked to comment on whether there was a need to identify the principles of auditing upon which the professional requirements of ISAs are set' (IAASB, 2004a, p. 18) and on whether ISAs should be restructured and requirements separated from explanatory material. Resolving these issues constituted the initial objectives of the Project but the objectives developed and changed as the project evolved.

The progress of the Project was rather tortured and there were a number of changes in direction during its evolution. The paper argues that this was 
due to a failure to adequately consider fundamental issues relating to the nature of auditing standards and their conceptual underpinnings at the outset of the Project. There was inadequate conceptual enquiry into concepts that were used in discussions between the IAASB and their constituents. Concepts such as 'principles of auditing' and 'principles-based standards', 'objectives' and 'objectives-based standards', a 'conceptual framework for auditing', 'requirements' and 'explanatory guidance' were used in discussions but not adequately examined or explained. The failure to be clear about these concepts and to consider the nature of auditing standards has resulted in 'clarified' standards that lack clarity. The Project constitutes a missed opportunity.

The objective of this paper is to undertake a conceptual enquiry into these concepts. An enquiry of this kind identifies the meaning of expressions as used in an area of discourse. It considers whether these expressions have a precise meaning or whether they are vague and whether the parties to the discussion agree on the use of these terms. The usefulness of the expressions is examined and the enquiry considers whether one meaning should be privileged over others or whether it would be more useful to abandon the use of such terms altogether (Dennis, 2008, pp. 261-4). Undertaking an enquiry of this kind is the method adopted in the work. Given that concepts 'direct our interest', if the meaning of expressions is not clear to those who use them or if they mean different things by them, then their interests can be misdirected and communication impaired (Dennis, 2008 , p. 263). It is argued that the progress of the Project and the questionable outcomes resulted from a misdirection of interests of both the IAASB and its constituents and that this resulted from inadequate conceptual enquiry. The paper begins to rectify this neglect.

The paper starts by illustrating some of the confusions that emerged during the evolution of the Project. These arose from a failure to adequately consider what was meant by the expression 'principles-based auditing standards' and to realize that this expression could be understood in different ways. Understanding this expression in one way resulted in the Project pursuing an objective of developing 'fundamental principles of auditing' and considering whether there was a need for a conceptual framework for auditing. This objective was eventually abandoned. Understanding the expression in a different way resulted in the objective of focusing on the development of 'objectives-based' standards. This nature of such standards is examined in conjunction with related issues about the nature of 'overall objectives' and 'objectives' in standards. The paper goes on to consider the relationship between 'objectives' and 'requirements'. The idea that requirements express rules is examined by considering two concepts of rules identified by Rawls (1955). This throws light on the nature of requirements, the kind of language used to express them and their relationship with 'objectives'. The nature of 'explanatory guidance' is also examined and its relationship with requirements considered. The paper ends by considering whether the Clarity Project has actually clarified the nature of auditing standards and whether the Project has given clarity to the auditing standards that have been reviewed.

\section{THE ORIGINS OF THE CLARITY PROJECT}

The Clarity Project emerged from the exposure of a draft of the Preface to International Standards on Quality Control, Auditing, Assurance and Related Services (Preface) and an Operations Policy No. 1 Bold Type Lettering (Operations Policy) in 2002. The Preface stated that existing auditing standards contain 'basic principles and essential procedures' identified by black or bold lettering. They also include explanatory and other material that provides guidance for their application which is identified in grey or plain type lettering. The Preface suggested that auditors have to exercise professional judgment in applying standards and that they can be overridden in certain circumstances (IAASB, 2003f, §14). The problem that dogged the Project from the start was the failure to fully consider what was meant by the key expressions such as 'basic principles and essential procedures' and 'explanatory material'.

Respondents to the Exposure Draft (ED) of the Operations Policy supported the use of bold lettering in order to identify 'basic principles and essential procedures'. This was thought to demonstrate a commitment to 'principles-based standards' and avoided a 'rule book' approach to standard setting (see comment letters of Association of Chartered Certified Accountants (ACCA), Fédérations des Experts Comptables Européens (FEE), PricewaterhouseCoopers (PwC) and the UK Auditing Practices Board (UK APB) in IAASB, 2003c). The nature of 'basic principles 
and essential procedures' was recognized as problematic at the outset. 'Basic principles' were not separated from 'essential procedures' and bold type sentences 'may be a mix of both' (IAASB, 2003b, §7). An IAASB staff proposal to replace these terms with 'main principles' was rejected by the IAASB on the grounds that it suggested that there might be 'secondary principles' which was not the case (IAASB, 2003d, §5). The expression 'fundamental principles and procedures' was said to have 'general support' (IAASB, 2003h, §8) but the term 'fundamental principles' was thought preferable given 'there are not fundamental procedures but rather procedures derived from fundamental principles' (IAASB, 2003g, p. 15). The change in names is symptomatic of disquiet about their nature.

The Task Force appointed to guide the Clarity Project agreed with respondents that identifying such 'fundamental principles' demonstrated a 'principles-based approach' to standard setting. It facilitated 'the identification of the broad objectives' or the overarching 'thrust' of a Standard (IAASB, $2003 \mathrm{~h}$, §9) that was seen as an important aspect of a 'principles-based approach'. However, the use of bold and plain type lettering in auditing standards raised the question of the 'authority' of statements using different lettering. Some respondents to the ED of the Operations Policy suggested that the IAASB should follow the International Accounting Standards Board (IASB)'s lead in financial reporting standards and include a statement that sentences in both kinds of lettering have 'equal authority' (IAASB, 2003e, \$2). The IAASB was concerned though that this might confuse practitioners as to 'whether a specific statement represents a fundamental principle, fundamental procedure, or explanatory guidance'. The IAASB asked the Task Force to clarify 'the interrelationship between these concepts' (IAASB, 2003g, p. 15). It is odd for both the IAASB and its constituents to contend that 'fundamental principles of auditing' are important without agreement on what they are and how they are related to procedures and guidance. It may be that each of these parties is clear about meanings but that there is no agreed understanding on what they are.

\section{FUNDAMENTAL PRINCIPLES OF AUDITING}

A Discussion Paper 'Improving the Clarity of IAASB Standards' was considered at a meeting of the IAASB in June 2004 (IAASB, 2004b). It included a set of 'fundamental principles of auditing' comprising 'the fundamental principles of professional ethics' and 'fundamental principles underlying the objective of an audit'. There appears to have been a shift in the meaning of 'fundamental principles' in the move from talking about 'basic principles' in auditing standards to 'fundamental principles' which 'underlie' the objective of an audit. The 'link' between and how 'principles' can 'underlie' an objective was not explained at this stage of the Project.

There were mixed views amongst IAASB members about the proposal to identify 'fundamental principles of auditing'. Some members supported 'a more structured, theoretical approach' to developing such principles and to determining the link between them and professional requirements. Others thought that although developing such 'principles' may assist the IAASB as a standard setter this would be of little benefit to practitioners. It was felt that pursuing this objective may detract from the efforts to improve the clarity of standards. Still others thought such 'principles' might assist the professional in the conduct of an audit. This suggests that there was still discomfort over the term 'fundamental principles of auditing' and also about their role and who they were for. The Task Force was asked to consider whether this expression should be replaced by 'principles underlying an ISA audit'. Hedging its bets, the IAASB also stated that if proposals were exposed 'it should be made clear that resolution and agreement on the fundamental principles of auditing is not a prerequisite for the clarity proposal to proceed' (IAASB, 2004b, p. 14). An ED of a Proposed Policy Statement and Consultation Paper was issued in 2004 (IAASB, 2004a). Together these are referred to as the First ED. The IAASB asked respondents for guidance as to whether it was necessary to 'identify the principles of auditing upon which the professional requirements of ISAs are set' (IAASB, 2004a, §6). A set of proposed 'fundamental principles' was included in the First ED.

A number of respondents to the First $E D$ supported the objective of identifying 'fundamental principles'. There was general agreement they would establish 'a basis for determining the extent and specificity of requirements' (IAASB, 2005c, p. 2). Some respondents said that this evidenced a 'principles-based' or 'objectives-based' approach 
to standard setting. The International Organization of Securities Commissions (IOSCO) argued that international auditing standards need to be principles-based' and 'should contain substantive objectives and clear principles that are consistent with a sound conceptual framework' (IAASB, 2005d, p. 1272). KPMG agreed that such a framework would give 'the necessary foundation under which existing and future individual ISAs can be drafted and organized' (IAASB, 2005d, p. 1276). PwC suggested that a framework would 'guide the application of professional judgement by auditors in designing and performing audit engagements to achieve the objective of the audit' (IAASB, 2005d, p. 1283). The FEE stated that 'a 'principles-based' or 'objectives-based' system is one in which 'specific objectives must be achieved at each stage of an audit in support of the overall opinion, but in which the procedures set out in the standards as necessary to achieve those objectives are limited to those that are essential and where other procedures have to be developed by the expert auditor to fit the circumstances'. A " "rules-based" or "detailed procedures-based" system is one that loses sight of the objectives and focuses on required procedures' (IAASB, 2005d, p. 1262). The Institut der Wirtschaftsprüfer (IdW) agreed and thought that the First ED 'does not appear to be principles-based because it concentrates on the requirements (i.e., rules regulating auditor input, or procedures) and there is little reference to the objectives to be achieved'. They supported a 'top-down approach' that 'would highlight the fact that it is essential for the professional accountant to establish what to achieve and why before addressing professional procedural requirements, considering guidance, and applying professional judgement in selecting alternative or additional procedures designed to achieve a particular objective'. They went on to say that 'it must be clear to the professional accountant what must be achieved and why, and then what must, or may need to, be done to achieve these objectives ... The IAASB has hitherto not accorded a high priority to the identification of these objectives; consequently, the IAASB standards are not as principles-based as they ought to be (IAASB, 2005d, p. 1271).

Respondents appear to have different understandings of what is entailed by a 'principles-based' or 'objectives-based' approach to standards. Although there is support for the development of a framework for auditing, some suggest that it is for standard setters while others suggest that it is for auditors. Some respondents appear to think that being 'principles-based' is a matter of being based on 'principles', while others suggest that auditing standards should contain them. Being 'principles-based' sometimes means including objectives in auditing standards and sometimes basing auditing standards on objectives in some kind of framework. There is little recognition that different conceptions might be involved.

In the context of financial reporting there are two meanings of 'principles-based' accounting standards (Dennis, 2008, p. 265). A 'principlesbased' accounting standard can mean one that is derived from a conceptual framework. Given that a conceptual framework is sometimes referred to as a 'statement of principles' (Accounting Standards Board, 1999) it is not surprising that accounting standards based on or derived from a conceptual framework might be referred to as 'principlesbased'. David Tweedie used the term in this sense in testimony given to the US Senate Committee on Banking, Housing and Urban Affairs (Financial Accounting Standards Board (FASB), 2002, p. 5). This is also the sense in which the FASB and the IASB sometimes talk of accounting standards as being 'principles-based' (FASB/International Accounting Standards Board, 2005, p. 1). Schipper acknowledges that accounting standards are called 'principles-based' if they are based on a conceptual framework but also notes that such standards can be 'rules-based' in that they have certain characteristics (Schipper, 2003, p. 62). One characteristic is that a 'principles-based' accounting standard includes a statement of 'substantive accounting principle' that 'incorporates' the 'accounting objective' in the standard itself. Other characteristics include that such standards contain few, if any 'exceptions or internal inconsistencies', provide an 'appropriate amount of implementation guidance' and are devoid of 'bright-line tests' (SEC, 2003, p. 12). It is unclear how many of these characteristics an accounting standard has to have in order to be 'principles-based' (Dennis, 2008, p. 266). This alternative explanation allows the possibility that accounting standards might be 'principles-based' in that they are based on 'principles' in a conceptual framework but do not have the relevant characteristics. Schipper seems to suggest that such standards have to be both based on a conceptual framework and have certain characteristics to be 'principles-based'. 
The shift between these two meanings of 'principles-based' was evident in the evolution of the Clarity Project. It appeared to start with the idea that being a 'principles-based' auditing standard was a matter of having certain characteristics, namely containing 'principles' or 'objectives'. The idea was then introduced that it meant being based on some kind of framework. When the search for 'fundamental principles of auditing' was abandoned, being 'principles-based' reverted to being an auditing standard with certain characteristics, containing objectives for example. However, as will be seen, the desire amongst the constituents of the IAASB to articulate some kind of framework for auditing as a way of demonstrating the 'principles-based' nature of ISAs remained.

Given support for the approach, the Task Force presented a proposal at the June 2005 meeting of the IAASB to develop 'fundamental principles of auditing'. This was rejected by the IAASB though. It was felt that it offered 'the least direct benefit in terms of clarifying the IAASB's standards, including how they are to be drafted in the future, and in terms of influencing auditor behaviour' (IAASB, 2005b, p. 13). Such a development would consume too much time and needed a 'separate, properly scoped future project' rather being a component of the Clarity Project. The IAASB accepted an idea presented by the Task Force that 'for all intents and purposes, "principles-based" and "objectivesbased" standards, as used by respondents, are broadly equivalent' (IAASB, 2005c, §35). They felt that 'the "principles-based" nature of IAASB's standards may be demonstrated better, and made more effective, through the identification of objectives than by the proposed principles' (IAASB, 2005b, p. 14). It was agreed that 'each ISA should clearly identify, in a separate section of an ISA, the objective(s) to be achieved by the auditor' and that 'the auditor should have an obligation to meet the stated objective(s)' (IAASB, 2005b, p. 14). There seems to have been a shift back from the idea that being 'principles-based' is a matter of being 'based on' a framework of 'principles' to the idea that it is a standard that contains 'principles', or 'objectives' as the new terminology referred to them.

The idea that a 'principles-based' auditing standard is one that includes objectives may have been derived from the explanation of the nature of 'principles-based' accounting standards suggested by the SEC. 'Principles-based' accounting standards are those that 'clearly state the accounting objective of the standard' (SEC, 2003 , p. 5). For the SEC 'each standard is drafted in accordance with objectives set by an overarching, coherent conceptual framework' (SEC, 2003, p. 12). There is thus a link between the two explanations of why standards are 'principlesbased'. The objectives that are required to be stated in a standard are connected with the objectives in a conceptual framework. The problem for the IAASB was that there was currently no such framework. If auditing standards that are 'principles-based' require a conceptual framework, then there must be a proxy for such a framework. The lack of a clear understanding of what is meant by 'principles-based' auditing standards is not surprising given the origins of this idea in the financial reporting realm.

\section{SUBSEQUENT DEVELOPMENTS}

At a meeting of the IAASB in September 2005 it was reported that the IAASB Clarity Forum (Forum), a group of regulators, oversight authorities, national auditing standard setters, accounting firms, professional accountancy organizations and IFAC committees, had given broad support for the inclusion of objectives in standards. They agreed that there should be a 'focus on outputs rather than inputs' (IAASB, 2005f, §5). Forum participants noted that 'it will be important that the objectives are complete and sufficiently specific in order to be effective, and that there should be a clear linkage between the objectives and the requirements of an ISA' (IAASB, 2005f, §7). The IAASB meeting reviewed ISAs that had been redrafted to include objectives and noted that the objectives of the proposed redrafted ISAs are inconsistent and in some cases overlap'. It was agreed to review them before finalizing them for exposure (IAASB, 2005e, p. 5). In October 2005 the IAASB issued another ED proposing amendments to the Preface and included four redrafted ISAs in accordance with new drafting conventions (this is referred to as the Second ED). The Second ED states that the professional accountant must achieve the objective stated at the beginning of each Standard that is relevant in the circumstances of the engagement' (IAASB, 2005a, p. 5).

An analysis of respondents' comments on the Second ED reported, once again, strong support for objectives-based standards (IAASB, 2006c, p. 1). 
However, a number of respondents were worried about the 'piecemeal approach' to specifying objectives on a 'case-by-case basis' and thought that this might result in 'over-detailed objectives' or 'incompleteness' in objectives. Some respondents took up the IdW suggestion of a 'topdown approach' to the development of objectives. They wanted a 'single overarching objective of the auditor derived from the general objective of an audit' (IAASB, 2006c, p. 1). The Task Force noted that this approach might require the development of a framework but that this had been rejected previously by the IAASB. They did report that they were considering a 'top-down' approach whereby 'the objective of an audit in ISA 200 is used as the basis for an overall objective for the auditor that is more operational in nature' (IAASB, 2006c, p. 2).

At a later meeting of the IAASB, the Task Force recommended that an 'overall objective of the auditor should be specified, and the auditor should be required to achieve that objective, or to modify the report or withdraw from the engagement if this cannot be done'. This 'provides a primary focus on the end result, rather than the individual components, of the audit process' (IAASB, 2006f, p. 2). The 'obligation in respect of the individual objectives recognizes the context of the overall objective and the relationship amongst the individual objectives' (IAASB, 2006f, p. 3). The IAASB agreed at the meeting that 'the description of the objective of an audit should be expanded to clarify that an audit is undertaken to enhance the degree of confidence of intended users in the financial statements' (IAASB, 2006e, p. 3).

Another version of the Preface was published in December 2006 that set out the overall objective. In fact it provided two 'overall objectives'. One was of an audit, namely 'to enable the auditor to express an opinion whether the financial statements are prepared, in all material respects, in accordance with an applicable financial reporting framework. It is undertaken to enhance the degree of confidence of intended users in the financial statements. ISAs, taken together, provide the standards for the auditor's work in fulfilling this objective' (IAASB, 2006b, §11). The other was of the auditor, namely 'to obtain reasonable assurance about whether the financial statements as a whole are free from material misstatement, whether due to fraud or error, and to report on the financial statements in accordance with the auditor's findings' (IAASB, 2006b, §12).
An ED of a clarified ISA 200 was issued in April 2007. A meeting of the IAASB received feedback from the European Commission (EC) that the obligation relating to achievement of the ISA objectives in ISA 200, which derived from the Preface, needed revision. The IAASB explained that because the Preface may not be reproduced or adopted in certain jurisdictions, the IAASB agreed to revise extant ISA 200 to incorporate provisions of the Preface relevant to ISAs ... When completed, the Preface would be amended to refer readers to the revised ISA 200 for the authority attaching to ISAs' (IAASB, 2008a, § 1). The point was that if the Preface contained obligations that professional auditors had to take notice of, then these obligations would have to appear in an ISA and not in the Preface itself. This raises the question of who the Preface is for. If it was for the standard setter then it does not matter that objectives are included in the Preface. It is only if the Preface contains obligations for the professional that these obligations would have to be included in an ISA.

Respondents to the ED of ISA 200 noted that 'significant confusion arises from having two objectives stated (i.e. one for the audit and another for the auditor)' and they were not convinced of the need for both. The majority thought that only the overall objective of the auditor was needed (IAASB, 2008a, §7). If an objective is something that is to be achieved by the actions of auditors and an audit is a series of auditor's actions, then in both cases the objective is something to be achieved through auditors doing something. It makes little difference if the objectives are characterized as the objectives of auditors undertaking the actions or the objectives of the actions undertaken by auditors. It is redundant to have two objectives.

A single statement of the overall objectives of the auditor was included in ISA 200 and the objectives were removed from the Preface. The title of the ISA was also changed to reflect the inclusion of relevant provisions of the Preface. It became 'Overall Objective of the Independent Auditor, and the Conduct of an Audit in Accordance with International Standards on Auditing'. In a review of a Proposed Strategy Paper issued in October 2007, 'there were a number of respondents who were of the view that the IAASB should start to develop a conceptual framework, believing that it would assist the IAASB in writing principles-based standards' (IAASB, 2008b, p. 18). The support was not unanimous and 
some members were of the view that this would divert too many resources, an argument that had led to the abandonment of this objective earlier in the Project. Some IAASB members 'were not sure what such a framework would be used for or how it would expand upon the concepts of proposed ISA 200 (Revised and Redrafted) and the assurance framework as it currently exists'. One member suggested that it could be that what is being called for actually exists within the ISAs, albeit in different places, and suggested that material in proposed ISA 200 (Revised and Redrafted) could be moved to a separate paper' (IAASB, 2008b, p. 19).

The idea that auditing standards are 'principlesbased', in that they are based on 'principles' in a framework, seems to have crept in by the back door. With the rejection of a search for 'fundamental principles of auditing' or a conceptual framework for auditing being 'principles-based' becomes a matter of including objectives in a standard rather than standards being based on a framework of 'principles'. Formulating an overall objective for the auditor and requiring standards to be based on such an objective suggests that ISA 200 has become a proxy for a framework. Given that ISA 200 is an auditing standard it would appear that the distinction between standards and a framework for standards has become muddied. This raises the more general question of to whom auditing standards are directed. As noted above there were different views as to whom 'principles' were directed. Were they for the standard setter or for professional auditors or both? If objectives are included in standards as a proxy for 'principles' in a framework then the question arises as to whom the statement of objectives in ISAs are directed and, by implication, raises the question of who standards are for. The question of the connection between the 'principles' or 'objectives' in ISA 200 and other objectives or requirements in ISAs also arises. It may be easier to understand these issues by considering the nature and role of 'principles' in a framework, such as a conceptual framework, and their relationship with auditing standards.

\section{THE NATURE AND ROLE OF ‘PRINCIPLES' IN A CONCEPTUAL FRAMEWORK FOR AUDITING}

Understanding the nature and role of a conceptual framework for auditing will not be advanced very far by considering what is written about the conceptual framework for financial reporting. This was not something that the joint project to revise such a framework currently being undertaken by the IASB and the FASB explored very fully (Dennis, 2006). The IASB and the FASB characterize a conceptual framework for financial reporting as something that 'both Boards can use in developing new and revised accounting standards' (FASB/IASB, 2005, p. 1). The UK's Accounting Standards Board (ASB) also agrees that the 'primary purpose of articulating such principles is to provide a coherent frame of reference to be used by the Board in the development and review of accounting standards' (ASB, 1999, §1-2). It is important to understand the role of such a framework in assisting standard setters.

One way of interpreting the claim that a conceptual framework can assist standard setters in setting auditing standards is to take it as giving reasons for promulgating auditing standards. This is the role identified by the IdW in their comment letter on the First ED when they suggest that 'fundamental principles underlying an ISA audit' comprise 'the reasons behind audit objectives'. They 'underlie the professional requirements in the ISAs' (IAASB, 2005d, p. 50). The problem with conceiving a framework in this way is that the concept of a 'reason' is unclear. One can have reasons for believing something or reasons for doing something. The nature of reasons needs to be made clear. Some help in understanding reasons is given in the philosophical literature. The idea of a reason is explained in relation to reasoning (Hacker, 1996, p. 58). Providing reasons for promulgating standards can be understood as expressing something that appears as a premise in a certain kind of reasoning. The nature of the reasoning must itself be made clear. Mattessich suggests in the context of accounting standard setting that accounting standards have a 'purposeorientation' (Mattessich, 1995, p. 259). Decisions relating to such standards should be understood as the outcome of 'instrumental' or means-end reasoning (Mattessich, 1995, p. 272). Such reasoning has the logical form:

I want to attain end $E$ under circumstances $C$.

Choosing means $\mathrm{M}$ will achieve end $\mathrm{E}$.

I want to choose means $\mathrm{M}$.

The first premise expresses a desire or what might be called the objective or outcome that is to be 
achieved by performing an action. The second premise is generally understood as an empirical one that sets out a belief as to how the objective is to be achieved by a particular action which is believed to be the means of achieving the objective. This might involve a belief about how performing the action will cause the end to come about. The conclusion expresses a desire to perform the action that will fulfil the desire or bring about the outcome. If the action is performed as a result of wanting to perform it the reason for the action is given by the premises of the practical reasoning. One performs an action, choosing means $\mathrm{M}$, because one wants to attain end $\mathrm{E}$ and believes that the action will result in the end being achieved. To take an everyday example, if one wants a cup of tea and believes that putting on the kettle will help to achieve this end, then one may want to put on the kettle. If one performs the action of putting on the kettle as a result of wanting to do so then the reason for doing so is that one wants a cup of tea. In the philosophical literature, reasoning of this kind is referred to as 'practical reasoning' (Anscombe, 1957, p. 62). It is characterized as reasoning undertaken by an agent who has a desire to achieve outcome to a conclusion that is a desire to perform some intentional action that is believed to result in the outcome being achieved (Dennis, 2010, p. 139).

Intentional actions might be described as 'objectives-based' or 'objectives-oriented' because they are performed for reasons that include desires or objectives. Further questions might be asked about these desires. Someone might ask 'Why do you want to make tea?'. The answer might be 'Because I am thirsty and want to slake my thirst'. Although it is usually unnecessary to elaborate on reasons, there is an unstated belief that making tea will help to bring it about that my thirst is slaked. This belief and the desire to slake thirst constitute the reason for the intentional action. The action can be re-described on the basis of the desires identified. If one makes tea because one wants to slake one's thirst, then one can be described as doing something to slake thirst or slaking thirst. There comes a point when such questioning ends. This is the point at which the thing wanted is characterized as desirable. Most people agree that slaking thirst is desirable. This is accepted as a 'good' reason for the action in question. It has a 'desirability-characterisation' (Anscombe, 1957, $\S 38)$.
Although auditors may decide what to do on each separate occasion where a procedure is required, this would be rather time consuming. What they might do instead is to decide what to do whenever certain kinds of circumstance arise. They might reason about what to do in general. This would require that the first premise expresses something that is wanted generally. The second premise would then express a belief that also has generality. The auditor must consider what actions will bring about the desire in general. The conclusion is not a desire for a specific action but a desire for actions that are wanted more generally, that is, as a rule. Instead of prescribing actions to be followed on particular occasions the conclusion prescribes rules about what to do generally.

A rule, in this sense, is 'a general prescription guiding conduct or action in a given type of situation. A typical rule in this sense prescribes that in circumstances $\mathrm{X}$, behaviour of type $\mathrm{Y}$ ought, or ought not to be, or may be, indulged in by persons of class Z' (Twining \& Miers, 1976, p. 48). Such rules are 'inherently general, laying down standards of correctness for a multiplicity of occasions' (Baker \& Hacker, 1985, p. 44). The auditors may prescribe themselves a rule in order to guide their conduct when the circumstances are appropriate. This innocuous suggestion is open to misunderstanding. The word 'rule' has been hijacked in discussions of financial accounting standards where it is used to refer to a particular kind of rule, one that is 'rules-based', rather than a rule in a generic sense. Such rules are contrasted with another kind of rule, one that has the characteristics of being 'principles-based'. This refers to rules that have certain characteristics suggested by the SEC and not to rules that are 'based on' principles in a conceptual framework.

This image of individual auditors setting themselves rules through practical reasoning is not really applicable in the context of current auditing practice. Auditors do not set themselves rules to guide their behaviour in auditing situations. Auditing is an 'institutional practice' in the sense that auditors will do what is required by auditing standards because this is 'required by an institution whose authority is accepted' (Dennis, 2010, p. 140). It may also be a 'legal practice' in certain jurisdictions where laws are prescribed by the legislature and followed by professionals because of the authority of the legislature. Auditors do not follow rules of their own making but follow those 
promulgated by institutions or by the law. These rules state requirements. Practical reasoning is still relevant in these contexts but it is undertaken not by individual auditors but by standard setters in an institutional practice, or by the legislature in a legal practice. It is used to decide on what rules to promulgate in auditing standards. The reasoning would be of the kind:

'I (= institutions/the legislature/regulator) want auditors to achieve $\mathrm{Y}$

I believe that promulgating regulation/law $X$ will achieve $Y$

I want to promulgate regulation/law $X^{\prime}$ (Dennis, 2010, p. 140)

The ' $Y$ ' in the first premise might be something like that expressed in ISA 200, namely an outcome like auditors having reasonable assurance about certain matters that enables them to express an opinion (IAASB, 2009a, §11). The second premise is itself based on a number of other empirical premises. The reason why an institution like the IAASB believes that promulgating standards will achieve the desires in the first premise is that they believe that these standards will be adopted by regulators or legislators, for example, by the European Commission (Loft et al., 2006, p. 429). If the standard includes prescriptions that require auditors to perform certain procedures and professional auditors follow these standards, then it is believed that they will bring about the outcome desired. The IAASB state their belief that 'the use of clear, concise, consistent and definitive imperatives is essential to the consistent application of International Standards' (IAASB, 2004a, p. 6). These 'imperatives' are really prescriptions of rules. They are not imperatives like commands that are meant to be followed on only one occasion but are to be followed on a number of occasions where certain circumstances exist.

Auditing standards that contain rules, in this generic sense, may or may not contain rules of a particular kind, say a 'principles-based' or a 'rules-based' kind. These standards prescribe certain procedures that, if followed, will result in the achievement of the desires in the first premise of the practical reasoning. One sense in which standards are 'principles-based' or 'objectivesbased' is that they are believed by standard setters to result in the fulfillment of desires or objectives if they are followed by auditors. The standard setter's action in promulgating standards can be re-described as doing something that will result in the achievement of these objectives.

It is important that the standard setter is clear on what they want auditors to achieve and hence on what is wanted or desired to be achieved in promulgating standards. Another way of making the same point is to say that they must agree on the objectives of setting auditing standards or on what desires are characterized as desirable. It is easy to see why agreeing on objectives might be thought to be something that is part of a framework for auditing. It establishes part of the reason for promulgating standards that include rules that require auditors to undertake procedures. Such a framework assists the standard setter in the activity of standard setting by providing reasons for setting standards.

Frameworks may have other purposes. They may inform professionals of the reasons why the standard setter is promulgating standards. This gives some point to informing auditors of the reasons why standards are promulgated by including a statement of objectives in a conceptual framework or in a proxy like ISA 200. The IAASB, like other standard-setting bodies such as the FASB in the financial reporting area, has 'little defense against the criticism that it does not have legitimate authority'. A conceptual framework may provide 'the rationalization for its choices' which might not be needed if 'a more representative body were to take over the function of setting accounting standards' (Dopuch \& Sunder, 1980, p. 17). Conceptual frameworks are 'a means of enhancing ... standard-setting powers' (Archer, 1993, p. 66) or as a device to 'boost... public standing' (Dopuch \& Sunder, 1980, p. 17). They legitimize standards (Hines, 1989, p. 85). This is meant to be achieved by demonstrating that the standards are derived from agreed 'principles' set out in a conceptual framework. They show that standard setters promulgate standards for 'good' reasons, that is, these reasons include desires that are characterized as desirable. These reasons include the desires that are to be found in frameworks like the conceptual framework. Saying that a 'principles-based standard' is one 'based on' or 'derived from' 'principles' in such a framework can be understood as suggesting that promulgating standards is the outcome of practical reasoning from desires or objectives that have a 'desirability-characterisation'. Standards are 'principles-based' if they are promulgated for these reasons. 
The desire for 'principles-based' standards, understood in this way, gives rise to a desire to construct a framework. This accounts for the demand of some of the respondents to EDs issued during the evolution of the Clarity Project that the IAASB develop a framework for auditing. Such a framework not only expresses the objectives or desires that are to be used by the standard setter in practical reasoning to auditing standards, but also demonstrates to governments, regulators and professional auditors that standards are promulgated for 'good' reasons. This enhances the legitimacy of a standard setter like the IAASB. If due process is followed in agreeing on objectives or desires in such a framework, then it would be difficult to reject auditing standards if it could be shown that they are derived from these agreed desires. Without such a framework the legitimacy of the IAASB may be called into question. The abandonment of the project to develop a framework for auditing might be viewed as a missed opportunity.

The IAASB and some of its constituents turned their attention to articulating the overall objectives of the auditor in ISA 200 as a proxy for such a framework. One reason why including what amounts to a statement of reasons for promulgating a standard in a standard is that it is useful to make the auditor aware of why there is a requirement for them to perform auditing procedures. This might result in them undertaking such procedures not simply because it is required by a standard setter but also because there are 'good' reasons for doing so. If they accept these reasons and perform the action, at least in part, because they believe that the objective is desirable, then their action can be re-described as doing something to bring about that the desire is fulfilled. There is nothing contradictory in saying that auditors may perform actions because they want to fulfil the desire that prompted standard setters to promulgate an action and also because they want to do what the standard setter requires them to do and believe they have the authority to demand it. There can be a number of different descriptions of what is done given that there are a number of different reasons for doing it (Goldman, 1970, Chapter 2). In this sense a statement of principles is not just for the standard setter but also can be for professionals if it provides reasons for their wanting to undertake certain actions as part of their professional responsibilities. The IAASB seem to have been forced to include this information in an
ISA rather than in a separate framework because in some jurisdictions only auditing standards are recognized. This was why the statement of objectives was removed from the Preface to standards into a standard itself. This suggests that they thought that the statement of overall objectives was for the auditor as well as for the standard setter. If this is the case then how such statements are to be used by the auditor must be explained in addition to explaining the role of a statement of objectives for the standard setter. The one role may need to be differentiated from the other. This will become clearer if the overall objectives are considered more closely.

\section{THE OVERALL OBJECTIVES OF THE AUDITOR IN ISA 200}

In the final version of ISA 200 the overall objectives of the auditor are 'to obtain reasonable assurance about whether the financial statements are as a whole free from material misstatement, whether due to fraud or error, thereby enabling the auditor to express an opinion on whether the financial statements are prepared, in all material respects, in accordance with an applicable reporting framework' and 'to report on the financial statements, and communicate as required by the ISAs, in accordance with the auditor's findings' (IAASB, 2009a, §11). The reference to 'enhancing the degree of confidence' that was originally part of the overall objectives was deleted and is now included in the Introduction section of ISA 200 where it is described as 'the purpose of an audit' (IAASB, 2009a, §3). The difference between a 'purpose' and an 'objective' is not explained. An even more fundamental flaw is the failure to consider the nature of objectives during the evolution of the Clarity Project.

The idea of an objective in other contexts is also not clear. A dictionary definition of the word 'objective' explains that it is 'the point to which the operations (esp. of an army) are directed' (Chambers Twentieth Century Dictionary). This is itself ambiguous. The 'point to which operations are directed' might be interpreted as some action that the army is supposed to undertake, taking a hill for example. Alternatively, it might mean some outcome that is to be achieved by the operations of the army, say, the defeat of the enemy. The context in which the objective is stated normally makes it clear what is being expressed. In a briefing meeting a command of the form 'the objective of today's 
campaign is to take the hill' makes it clear to soldiers that they are required to perform some action, taking the hill. This kind of objective is simply a command or requirement that soldiers do something. It prescribes an action.

If the commander says 'the objective of today's campaign is to defeat the enemy' then the point of the command needs to be considered. It may be that the commander is telling soldiers what they must want to achieve. In other words, it is telling them what they must desire. This might be so that they can use practical reasoning to reason from this desire to the desire to act in a certain way. What the soldier has to do is to determine what actions will bring about the required result. The commander may be commanding soldiers to want something but leaving it to them to determine how to fulfil the desire. Another explanation of expressing such an objective might be that the soldier is being informed of the reason for other commands. This may give added force to these commands because the soldier now knows the reason why they are required. It is also possible that this objective is stated to assist the soldier in determining how to follow the command where it is not quite clear what the command requires. If the soldier knows the reason for the command then this might guide them in 'interpreting' the command. Objectives of this kind prescribe a desire.

A commander might issue a hybrid command. He might say 'the objective of today's campaign is to take the hill in order to bring about the defeat of the enemy'. What is the point of such a command? Is it the prescription to the soldier to do something, take the hill? It would probably go against the soldier if they did not take the hill but did something else that they believed would bring about the defeat of the enemy. The commander might say that the soldier disobeyed his command and should be disciplined. The point of mentioning the end may be only to inform the soldier of the reason for the command and not to invite the soldier to determine the means for themselves. This kind of command would seem more likely to be a prescription of action rather than the prescription of a desire although it may also have the purpose of informing the soldier of what it wanted to be achieved in prescribing an action.

This suggests that it is important to ask the point of stating an objective in order to understand the nature of the objective. This is also the case with stating objectives of auditing in ISA 200. Are the overall objectives stated to inform auditors of what they have to do or what they have to want or the reason why standard setters require auditors to undertake certain actions in ISAs? The Clarity Project does not acknowledge the ambiguity in the idea of an objective. The meaning of 'objectives' included in a statement of overall objectives is not clearly explained. What are they and who are they for?

What makes it difficult to determine what the objective is stating is that it is expressed in language that makes it look as though it is prescribing an action rather than stating a desire. The reason for this is that the kind of desire that constitutes a reason for action in practical reasoning is not an idle wish or hope that some outcome, an event or state of affairs, will result. What is wanted is to do something that will bring about a result. Someone who wants some end but does nothing towards getting it does not have the kind of desire that is expressed in practical reasoning (Anscombe, 1957, §36). The desire is 'action-oriented'. It is a desire to do something. Given this desire a person looks around for an action that will fulfil the desire. In the kind of practical reasoning that standard setters undertake in order to reason to a desire to promulgate auditing standards the desire is for auditors to do something to bring about a certain result. In ISA 200 the overall objective of the auditor is 'to obtain reasonable assurance ...'. This sounds like a prescription to auditors to do something, jthat is, to obtain reasonable assurance. However, another interpretation would be to say that it expresses a desire that auditors do something to bring about the event or state of affairs of having reasonable assurance. This desire is then used in practical reasoning by the standard setter who goes on to determine what has to be done by auditors in order to achieve this end. Having decided this, they promulgate requirements in ISAs for auditors to perform actions that will achieve this end. As with the command situation described above, the context in which the statement is made determines how it is to be understood. Is the point of stating the overall objective of the auditor to express a desire for an event or state of affairs that the standards setter is to use to promulgate requirements? If so, then it would appear to be a proxy for something that is included in a framework for auditing and will be used in the first premise in practical reasoning towards promulgating standards. Understood in this way an overall objective is for the standard setter. Is it to inform professionals of those reasons so that they will undertake 
procedures with the intention of doing something that will fulfil these desires? Understood in this way an overall objective may be used to enhance the legitimacy of the standard setter. It does not seem to be the prescription of a desire that the auditor is to have. The standard setter is not saying that the auditor must want to bring about the end of having reasonable assurance and then leaving it to the auditor to determine what they need to do to bring about this end. If this were the case then the requirements in ISAs would be redundant. Is the IAASB clear about the purpose of a statement of overall objectives?

Further confusions arise from the fact that expressing desires is not the only thing that is included in ISA 200. What is wanted is that there should be reasonable assurance that enables the auditor to express an opinion that is mandated by the law or by regulation. ISA 200 states that the opinion is about 'whether the financial statements as a whole are free from material misstatement, whether due to fraud or error' (IAASB, 2009a, §5) and on 'whether the financial statements are prepared, all material respects, in accordance with the applicable financial reporting framework' (IAASB, 2009a, §11). What constitutes 'reasonable assurance' depends upon the nature of the opinion required. Stating what kind of support is required explains what is meant by the opinion. What is 'reasonable' depends on the level of assurance required. ISA 200 explains that 'reasonable assurance' is 'a high level of assurance' and that this is obtained whether 'the auditor has obtained sufficient appropriate audit evidence to reduce audit risk ... to an acceptably low level'. Such evidence amounts to 'information used by the auditor in arriving at the conclusions on which the auditor's opinion is based' (IAASB, 2009a, §13). ISA 200 appears to have a dual purpose. It expresses the desire that standard setters have for auditors to achieve a certain end and also explains what it means to achieve the end. These two purposes correspond to the kind of thing that appears in a conceptual framework. In the financial reporting context such frameworks provide a statement of objectives which amount to a statement of what is desired or wanted from financial reporting. These frameworks also include explanations of the meaning of expressions used in financial reporting.

Although there is no clear statement of the purpose of stating an overall objective, if it is used in some way to support requirements then it is important to be clear about the nature of requirements and how they are related to a statement of overall objectives.

\section{REQUIREMENTS}

One way of understanding the nature of requirements in auditing standards is to take them as prescriptions or rules, in a generic sense, that require auditors to undertake procedures. The standard setter might believe that if auditors undertake these procedures then the desire expressed in the overall objectives will be fulfilled. The connection between overall objectives and requirements is thus made through practical reasoning. There is a desire expressed in a statement of overall objectives. There is also a belief that undertaking an auditing procedure will fulfil the desire. The conclusion is a desire for auditors to undertake the procedure. If a standard requiring such a procedure is promulgated and this results in auditors undertaking the procedure, then the desire will be fulfilled if the belief is correct.

This simple picture of the way in which standard setters decide on what auditing standards to promulgate is complicated by a number of factors. One problem that the standard setter faces in the auditing context is that when the standard setter prescribes rules they are not considered in isolation one from another. This is expressed in ISA 200 as the idea that 'to achieve the overall objectives of the auditor, the auditor shall use the objectives stated in relevant ISAs in planning and performing the audit, having regard to the interrelationships among the ISAs' (IAASB, 2009a, §21). If the second use of 'objectives' is replaced by the word 'requirements' then the point being made is that the requirements in ISAs are interrelated. The Task Force explained that specifying the overall objective 'provides a primary focus on the end result, rather than the individual components, of the audit process' and that some auditing methodologies 'do not reflect the structure of the ISAs' or 'require the individual objectives in the ISAs to be considered as specific building blocks to the overall objective' (IAASB, 2006f, \$7). Again, if 'objectives' is replaced by 'requirements' then this is saying that requirements need to be thought of as 'building blocks' that are 'interrelated' and, taken together and followed by auditors, will achieve the overall objectives of the auditor. In other words, the belief premise in the practical reasoning is not the belief that undertaking a single auditing procedure will result in the achievement of the 
overall objectives. It is rather that a number of procedures must be undertaken to achieve this end.

The nature of the 'interrelationships' was not clearly explained during discussions. The idea of 'bringing about' an overall objective can be interpreted causally. In scientific contexts 'events are enmeshed in a net of causal relations' and an 'explanation of why an event happens consists (typically) in an exhibition of salient factors in the part of the causal net formed by lines 'leading up to' it. These 'salient factors' constitute 'the cause(s) of that event' (Van Fraassen, 1980, p. 124). It is not one event or state of affairs that brings about the overall event or state of affairs desired but a number of events that are enmeshed in a causal net. Each of these events or states of affairs is desired in so far as they are part of this causal net. The standard setter desires that auditors bring about each of the events in the causal net necessary to achieve the overall objective.

Taken together these prescriptions or requirements are a kind of recipe that, if followed, is believed to achieve the overall objectives of auditing. This is not a new idea. Setting out rules in accounting in a 'recipe' is sometimes dismissed as adopting a 'cookbook' approach to accounting (West, 2003, p. 66). The analogy might also be applied to auditing. It is useful to consider the rules set out in auditing standards as a recipe for achieving the overall objectives of auditing. The analogy needs to be explored further. When one desires to make tea, for example, a recipe requires that a number of different events or states of affairs must occur. Different things have to be done to bring about these events or states of affairs. Sometimes one procedure cannot be performed until others have been undertaken. It may not be possible to mix boiling water with tea leaves unless one has boiled the water in advance and put the tea leaves into the tea pot. Each of the procedures can be looked on as bringing about events in a causal net that results in achieving the overall objective that the tea is made. Auditing procedures can also be viewed as a 'recipe for auditing'.

One problem that faces auditing standard setters is also faced by cooks who devise recipes. There may be a number of ways of bringing about certain events. There may be a number of ways of making tea. One can use tea bags or leaf tea. One can make it in a mug or in a teapot. Similarly, there may be a number of different causal nets that have the result of achieving the overall objectives of auditing. This can be expressed in terms of sufficient conditions. A causal net of events may be a sufficient condition of achieving the overall objectives of auditing. This can be expressed in the form 'if $p$ then $q$ ', where $p$ is a sufficient condition for $\mathrm{q}$. In auditing, doing $\mathrm{X}, \mathrm{Y}$ and $\mathrm{Z}$, procedures prescribed in standards, will result in the achievement of what is desired, the overall objective of auditing. The individual actions $X, Y$ and $\mathrm{Z}$ bring about events that are parts of a causal net that will result in fulfilling the overall objective. One procedure is not sufficient to achieve the outcome. The fact that tea can be made in various ways means that some procedures may not be necessary to achieve the objective. A necessary condition can be expressed in the form 'if $\mathrm{p}$ then $\mathrm{q}$ ', where $\mathrm{q}$ is a necessary condition for $\mathrm{p}$ (Lemmon, 1965, pp. 28-29). In auditing, if you are achieving the objectives of auditing $(p)$ then you are doing $\mathrm{X}, \mathrm{Y}$ and $\mathrm{Z}$ (q). This can also be

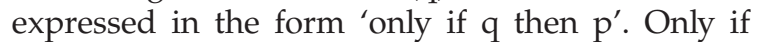
you are doing $\mathrm{X}, \mathrm{Y}$ and $\mathrm{Z}$ are you achieving the overall objectives of auditing. Standard setters need to consider both necessary and sufficient conditions in deciding on which standards to promulgate.

If doing $\mathrm{X}, \mathrm{Y}$ and $\mathrm{Z}$ a sufficient condition of bringing about the objectives of auditing then the standard setter may promulgate standards that require auditors to undertake such procedures. Matters would be simpler for the standard setter if there was one and only one way of achieving the overall objectives of auditing. The reality is that there may be other sufficient conditions that if brought about will achieve this result. If this is the case then doing $\mathrm{X}, \mathrm{Y}$ and $\mathrm{Z}$ is not a necessary condition of achieving it. This might be expressed by saying that there is no requirement to do $\mathrm{X}, \mathrm{Y}$ and $\mathrm{Z}$ in order to achieve the overall objectives. The idea of a requirement seems tied to the idea that it is a necessary condition. Respondents to the First ED doubted 'whether the requirements of a Standard are applicable in virtually all circumstances (particularly for auditors of smaller enterprises)' (IAASB, 2006c, p. 11). Respondents to the Second ED questioned 'whether each of the proposed requirements is necessary and applicable to entities of all sizes' (IAASB, 2006d, p. 6). The objective of obtaining reasonable assurance about whether the financial statements are materially misstated might be achieved by substantive testing alone rather than in conjunction with a systems approach. The causal net of events necessary to 
meet the objectives of auditing in large entities may not be the same as those necessary in small and medium sized enterprises (SMEs). In other words, respondents doubted whether the procedures were really required.

This can be interpreted empirically. It may be an empirical fact that an outcome will not come about unless a particular procedure is undertaken. The Clarity Task Force claims that 'certain requirements simply could not be replaced by the auditor with alternatives' (IAASB, 2005f, §32). The nature of the necessity is not discussed by the IAASB, but they do acknowledge that " "necessity" may be difficult to demonstrate and that it may preclude the auditor from choosing a more effective or efficient procedure' (IAASB, 2005e, p. 6). It may be difficult to prove empirically that a particular result can only be brought about by undertaking a certain procedure where there might be other ways, discovered in the future, for bringing about the result.

There is another interpretation of the necessity of procedures in standards. If, on whatever grounds, a particular procedure is deemed to be necessary then other procedures may be necessary as a matter of meaning. This may be because doing one thing means doing something else. This can be illustrated by ISA 230. It states that the objective of the auditor is to 'prepare documentation' that provides 'a sufficient and appropriate record of the basis for the auditor's report; and... evidence that the audit was planned and performed in accordance with ISAs and applicable legal and regulatory requirements' (IAASB, 2009b, §5). The requirements in ISA 230 explain what audit documentation is to be prepared. The documentation should be 'sufficient to enable an experienced auditor, having no previous connection with the audit, to understand... the nature, timing and extent of the audit procedures performed to comply with the ISAs and applicable legal and regulatory requirements ... the results of the audit procedures performed, and the audit evidence obtained', etc. (IAASB, 2009b, §8). These requirements follow from an explanation of what is meant by 'prepare documentation that provides a record of how the opinion was determined and evidence that ISAs and regulatory requirements were met'. Given the requirement of 'preparing documentation ...' and the meaning of 'preparing documentation...', the requirements in the ISA can be derived. The derivation may be deductive as long as the meaning of the expression that denotes a procedure gives a necessary condition of undertaking this procedure. In other words, the explanation is of the form 'if you are preparing documentation, etc., then you are preparing something that is sufficient to enable an experienced auditor, etc.'.

There is another explanation for the necessity of rules. They may be necessary in the sense that they are promulgated by an authority in a legal context where the rule must be obeyed. The IAASB may be motivated to issue requirements that have this kind of necessity where it is envisaged that the standards will be adopted as part of the law. This kind of necessity might be called an exigency of regulation. The problem for IFAC, and the IAASB that comes under it, is that they are private standard setters and not public ones (Loft et al., 2006, p. 433). They rely upon the acceptance of their standards by influential international organizations and, possibly, by their incorporation into law. Until they are adopted they do not have the authority or necessity of laws. The necessity must be otherwise grounded than in law. It was suggested above that a body like the IAASB may need something like a conceptual framework to give it a legitimacy that it does not otherwise have. A framework of this kind might be useful in demonstrating the necessity of such rules not because they are laws but because they are supported by good reasons not only for following them but for following them necessarily. The Clarity Project was given momentum by the announcement of the intention of the EU to apply the IAASB's auditing standards to all statutory audits in the EU. The IdW commented that they were worried that if ISAs were applied for audits of financial statements required by law or regulation then such standards become 'de facto or de jure legal instruments'. This was likely in the light of the 'the anticipated recognition of the ISAs in... the EU legal framework' (IAASB, 2005d, p. 22). Promulgating standards that have the necessity of laws would be attractive in this situation. However, with the grounds for this necessity unclear, the standard setter might have to rely upon adoption of such standards to justify a necessity that cannot be otherwise demonstrated.

Another problem for standard setters is that certain procedures may not always achieve the overall objectives of auditing. They may generally contribute to achieving this result, but this may not happen on every occasion. A cause has been described as 'an insufficient but necessary part of an unnecessary but sufficient condition' (Mackie, 
quoted by Van Fraassen, 1980, p. 114). In these circumstances the auditing procedure may not be a necessary part of a sufficient condition because the causal net of events brought about by the procedure is not a sufficient condition of achieving the objective on every occasion. ISA 200 allows a departure from a requirement 'where the requirement is for a specific procedure to be performed and, in the specific circumstances of the audit, that procedure would be ineffective in achieving the aim of the requirement' (IAASB, 2009a, §23). A procedure is not required, not necessary, where it is not part of a causal net of sufficient conditions of meeting an objective.

Even if a procedure is necessary to achieve an objective it may be that other procedures need to be undertaken in addition to those in ISAs in order to achieve the result on a particular occasion. ISA 200 states that the auditor shall 'determine whether any audit procedures in addition to those required by the ISAs are necessary'. This might require the exercise of professional judgement. ISA 200 offers a definition of 'professional judgement' as 'the application of relevant training, knowledge and experience, within the context provided by auditing, accounting and ethical standards, in making informed decisions about the courses of action that are appropriate in the circumstances of the audit engagement' (IAASB, 2009a, §13). Auditors have to make a decision about a course of action, namely whether to undertake other procedures not required by an ISA. Rather strangely they state that 'the auditor shall use the objectives stated in relevant ISAs' to determine this (IAASB, 2009a, §21). This only makes sense if the objective is an end, something desired, rather than a requirement. The auditor needs to consider whether the procedures required will bring about the desired result or not. This suggests another role for a statement of overall objectives. It is not just for standard setters who use it in reasoning to the promulgation of requirements but by auditors who need to use it to see whether anything else needs to be done in particular auditing situations that are not required by ISAs. If overall objectives are set out in frameworks for auditing then such frameworks might also be for the use of auditors.

If the nature of requirements and the reasons why they are 'required' had been explained in terms of necessary and sufficient conditions then the reasons for promulgating standards and for auditors following them would have been clarified. This is important because it has implications for the kind of rule that might appear in an auditing standard. The work of Rawls makes it clear that there are different kinds of rules.

\section{RAWLS' 'TWO CONCEPTS OF RULES'}

The IAASB undertook the Clarity Project 'to improve the clarity of its Standards, designed to meet the needs of the widest range of stakeholders and users of the Standards' (IAASB, 2006a, §2). The emphasis on the objectives of auditing and of the requirements in ISAs to those objectives suggests that the standard setter has a view of rules, understood in the generic sense identified above, whereby they are 'instruments of policies aimed at solving problems, that is to say as means to ends in problem situations' (Twining \& Miers, 1976, p, 69). A rule on an instrumentalist conception is one where the procedures required to be undertaken are a means to fulfilling certain 'ends'. These ends are the overall objectives of the auditor identified by the IAASB. Even if this conception of rules is adopted there may still be different concepts of rules though.

Rawls (1955) draws a distinction between two conceptions of rules. The first conception that Rawls describes is referred to as the 'summary' conception of rules. Rules of this kind arise because people have certain ends or desires that determine what they do. They notice that on a number of similar occasions acting in a particular way will achieve these ends. Different people may make similar decisions in similar circumstances. A rule is then formulated to cover cases of this kind. In effect, 'rules are pictured as summaries of past decisions' (Rawls, 1955, p. 158). They derive their point from 'the fact that similar cases tend to recur and that one can decide cases more quickly if one records past decisions in the form of rules'. Rules of this kind are conceived of as 'maxims and "rules of thumb" ' (Rawls, 1955, p. 162). Following the rule has been found to achieve an objective or fulfilled a desire in the past. Inductively, it is concluded that it will do so in the future.

The implication of this is that rules of this kind are believed to be a sufficient condition of fulfilling objectives. As noted above, in the auditing context rules in isolation are not sufficient conditions of achieving the ends but may be part of causal nets that are sufficient. If the causal net does not always achieve the objective then certain of the rules requiring procedures to be adopted may be overridden. Allowing an override requires the 
professional to use judgement as to whether to follow the rule or not. The exercise of professional judgement is one of the characteristics used to characterize a 'principles-based' system (ICAS, 2006, p. 1). However, this is a different kind of decision to deciding whether to undertake procedures not required by an ISA. One kind of decision about a course of action in auditing is whether or not to follow a rule in an auditing standard. A full examination of professional judgement is outside the scope of this paper. What is illustrated here though is that different kinds of decision require the exercise of different kinds of judgement. With rule of this kind 'each person is in principle always entitled to reconsider the correctness of a rule and to question whether or not it is proper to follow it in a particular case' (Rawls, 1955, p. 161). A standard setter may promulgate a rule of this kind if they accept that following the rule may not always achieve the objective and allow auditors to exercise judgement as to whether to override it or not. This is to treat the rule as a 'rule of thumb'.

The second idea of a rule is one conceived on the 'practice' conception. Rules of this kind 'are pictured as defining a practice' (Rawls, 1955, p. 162). It may be believed that leaving it to each person to decide what to do on specific occasions by considering what they want will lead to confusion. Instead the rule establishes a practice and this 'necessarily involves the abdication of full liberty to act on utilitarian and prudential grounds' (Rawls 1955, p. 162). This is not to say that the rule is not promulgated from such considerations. However, once the rule has been promulgated then there is no further consideration by practitioners of the reasons for adopting it. Accepting such a rule is acting in accord with it on all occasions where it is required, not only on those occasions which will fulfil the desires that prompted its original acceptance. The rule is not to be overridden. There is hence no need to state the objective in the standard for the purposes of override. Rawls suggests that the practice conception is more relevant to understanding legal and legal-like arguments than it is to the more complex sort of moral arguments' (Rawls, 1955, p. 170). In other words, the necessity is that of a law and depends on acceptance of the legitimacy of the rule maker. Rawls says that 'those engaged in a practice recognize the rules as defining it' (Rawls, 1955, p. 163).

Rawls observes that 'some rules will fit one conception, some rules the other; and so there are rules of practices (rules in the strict sense), and maxims and "rules of thumb"' (Rawls, 1955, p. 167). It is not clear which conception of rules is adopted by the IAASB. If auditing standards are to be adopted as laws in some jurisdictions then conceiving them on the 'practice' conception would enhance their acceptability. Conceiving auditing standards as 'rules of thumb' and allowing them to be overridden would appeal to those jurisdictions that wish to allow professional judgement to be exercised by auditors who can use the objectives to judge when to override the standard. In trying to satisfy both kinds of jurisdiction the IAASB may have been pulled in different directions in their conception of the kind of rule expressed in auditing standards. This may be why they sought to allow the override in 'exceptional circumstances'. The override may seldom be used. If so the rules will look more like rules on the 'practice' conception than 'rules of thumb' and the override may be no more than notional. The pressures exerted by the desire for convergence of standards seem to have resulted in a hybrid conception of rules that fudges a solution to the issue. The issue of the kind of rules expressed in standards should have been discussed in advance of the attempt to converge them. Understandably, this might have raised too many political issues and may have undermined the Clarity Project itself. Rules that can be incorporated in laws may not be the kind of rules that allow for the exercise of professional judgement of a certain kind. It is no wonder that the IAASB did not examine the nature of rules very carefully. This was another missed opportunity and resulted in considerable problems in deciding on the language used to express requirements in standards.

\section{THE LANGUAGE USED TO EXPRESS REQUIREMENTS}

Originally ISAs were said to contain 'essential procedures'. The problem was that they were not really essential if by this was meant that it was necessary to perform them on all occasions. The original Preface to auditing standards made it clear that they could be departed from 'in exceptional circumstances' in order to achieve 'more effectively' the objective of the engagement. In their comments on the ED of the revised Preface, IOSCO observed that it was important that professionals who followed auditing standards were able to 
ascertain what procedures are 'mandatory in all audits' and those that were not (IAASB, 2003c, p. 453). This was the thought behind the IAASB goal, quoted above, of making imperatives in standards 'clear, concise, consistent and definitive' through the language used. At the July 2003 meeting of the IAASB the use of 'shall' and 'must' was rejected on the grounds that they imply 'unconditional' which does not provide for 'professional judgement' (IAASB, 2003d, §5). This suggests a rejection of the 'practice' conception of rules in favour of a 'rules of thumb' conception. The IAASB was clearly pulled in two directions. If auditing procedures are mandatory then they need to be undertaken in all cases, but if this is the case then the use of 'judgement' to override them is not allowed.

At a subsequent meeting of the IAASB, it was noted that the US Public Company Accounting Oversight Board (PCAOB) had proposed to distinguish requirements by establishing 'new categories of unconditional ('must', 'shall', etc.) and presumptively mandatory ('should') requirements'. 'Unconditional requirements' were those where 'the professional accountant must accomplish requirements of this type in all cases in which the circumstances exist to which the requirement applies' and which are 'truly unconditional'. The IAASB proposed that the term 'unconditional requirement' be changed to 'mandatory requirements' and that 'only the term "shall" should be used to identify "mandatory requirements"' (IAASB, 2003i, p. 9). 'Presumptively mandatory requirements' were those where 'the professional accountant must comply with the requirements' unless 'in exceptional circumstances, the professional accountant judges that a departure from the requirement is necessary to more effectively achieve the principles contained in an International Standard or the objective of the engagement'. A requirement is not necessary if it can be departed from. Mandatory carries the implication of necessity. It would have been useful to relate these two categories of requirement to different kinds of rules along the lines suggested by Rawls but discussion did not proceed along these lines. Members of the IAASB focused instead on whether presumptively mandatory requirements 'imposed an undue level of obligation on practitioners' and were worried that the description of them did not adequately distinguish them from mandatory requirements (IAASB, 2003i, §7).
The First ED accepted the distinction and established two categories of 'requirements' using the expression 'shall' and 'presumptive requirements' indicated by the word 'should' (IAASB, 2004a, §4). The latter could be overridden 'in rare circumstances'. Respondents to the First $E D$ raised the same worry about whether the distinction was adequate with one-quarter of them thinking that the proposed distinction between the two categories was both insufficiently significant and difficult to make' (IAASB, 2005c, $\S 41)$. As the FEE noted, using the expression 'in rare circumstances' to indicate when 'presumptive requirements' can be overridden 'results in presumptive requirements that are so close to "shall" requirements as hardly to be distinguishable' (IAASB, 2005d, p. 1274).

At the Rome meeting in 2005 the IAASB agreed that they should revert to a single level of professional requirements that should be designated by the word 'should'. The Task Force recommended that departure from requirements would be allowed in 'those exceptional circumstances where the professional accountant judges it necessary to depart from the requirement to achieve more effectively the objective of the engagement' (IAASB, 2005c, §40). The meeting deleted the reference to 'more effectively' and allowed departure only where it was necessary to achieve the objective of the requirement rather than the engagement. The IAASB subsequently agreed on the use of the word 'shall' to indicate a requirement (IAASB, 2005e, p. 7). The Task Force had indicated in a Discussion Paper that 'the IAASB intends that its requirements are, in effect, essentially mandatory in all circumstances while accepting that all circumstances cannot be foreseen and that the auditor, exercising professional judgment, must be given the final say in what is done' (IAASB, 2005f, §21-22). Participants at the IAASB Clarity Forum that met in July 2005 agreed with a single level of requirement but raised a concern expressed in that 'ISAs would, under the proposal, contain no truly mandatory instructions'. At the IAASB meeting in New York, members agreed that this concern was misplaced (IAASB, 2005e, p. 6). The way ISAs are drafted with a high level of obligation in a requirement coupled with the use of objectives and procedures reflecting objectives ensured that 'certain requirements simply could not be replaced by the auditor with alternatives' (IAASB, 2005f, §32). This suggests that the grounds for necessity are that a particular 
procedure will be required in any causal net. It was noted by members that it 'will be incumbent on the IAASB to establish requirements that are relevant in virtually all circumstances and that can stand the test of time' (IAASB, 2005e, p. 6).

The Second ED established only 'requirements'. These were to be included in a separate section of the ISA and are identified by the word 'shall'. These 'requirements' are 'to be applied in all cases where they are relevant in the circumstances of the engagement. However, in 'exceptional circumstances' the professional accountant 'may judge it necessary to depart from a requirement in order to achieve the purpose of that requirement'. The need for the professional accountant to depart from a requirement is 'expected to arise only where the requirement is for a specific procedure to be performed and, in the specific circumstances of the engagement, that procedures would be ineffective' (IAASB, 2005a, §21). The Basis for Conclusions in the Explanatory Memorandum states that departure should be a rare occurrence and that 'relevant requirements are, in effect, essentially mandatory in all circumstances, while accepting that all circumstances cannot be foreseen and that the professional accountant must be given some latitude to exercise professional judgment when a requirement would clearly not be effective in the circumstances' (IAASB, 2005a, p. 19). Given the high level of obligation 'certain requirements simply could not be replaced by the professional accountant with alternatives. Accordingly, the IAASB concluded that there is little benefit in establishing a separate category of requirements that would declare certain requirements as specifically mandatory' (IAASB, 2005a, p. 17). Given the doubts expressed by respondents to the Second ED as to whether the requirements of a Standard were applicable in virtually all circumstances, ISA 200 states that a departure from 'relevant requirements' is possible 'where the requirement is for a specific procedure' and 'that procedure would be ineffective in achieving the aim of the requirement' (IAASB, 2009a, §23).

The position adopted identifies the requirements in ISAs as rules that appear to be a hybrid between 'rules of thumb' and rules on the 'practice' conception. A requirement is not of the kind 'always do A' but 'nearly always do A (except on the odd occasion when it will not achieve the aim of the requirement)'. It is not a necessity but almost a necessity. The solution is far from clear. The IAASB was pulled in different directions. If standards are to become part of the law in jurisdictions within the EU then they may need to be considered as expressing rules on the 'practice' conception. If a professional auditor is meant to exercise professional judgment to override rules then they need to be conceived as 'rules of thumb'. It is no wonder that the conception of rules adopted by the IAASB appears as a hybrid.

Auditing standards contain rules, albeit the nature of those rules is not clear. They also contain explanatory guidance. This is important since one characteristic of 'principles-based' standards referred to above was that they should provide an 'appropriate amount of implementation guidance'. ISAs contain a section on application and other explanatory material in addition to sections that set out objectives and requirements. What is that nature of explanatory material?

\section{EXPLANATORY MATERIAL}

The issue of the nature of explanatory material or guidance was raised during the evolution of the Clarity Project. At the outset of the Project the Task Force expressed a desire to define 'a drafting convention that focuses on fundamental principles and procedures, supported by clearly understandable requirements and explanatory guidance for their application' (IAASB, 2003h, p. 1). As noted above, the IAASB was concerned that practitioners might be confused as to the difference between a fundamental principle, fundamental procedure and explanatory guidance. The IAASB staff proposal for Improving the Clarity of IAASB Standards considered in July 2003 proposed that the description 'explanatory and other material' should not be retained (IAASB, 2003e, §19). Respondents to the ED of the revised Preface to auditing standards suggested that the grey type lettering in standards that were used to express explanatory guidance sometimes contained what seemed to be obligations, particularly those indicated by present tense sentences. IOSCO's comment letter suggested that 'readers of auditing standards must be able to ascertain clearly what procedures are mandatory in all audits, and what procedures are only applicable in certain specific cases' (IAASB, 2003c, p. 453).

The Task Force considered the nature of explanatory material in a proposed Policy Statement presented at the Berlin meeting of the IAASB in December 2003. They agreed that 'the link between explanatory material and the 
principles and professional requirements to which it relates' should be made clearer (IAASB, 2003i, p. 10). Explanatory material was 'intended to be descriptive rather than imperative' in that it 'provides an explanation of why the professional accountant should consider or employ particular procedures' (IAASB, 2003j, §15). The problem with this is that the nature of 'explanation' needs clarification. It might be understood as providing reasons for undertaking certain procedures of the kind that a standard setter would consider when deciding whether to promulgate an auditing standard. These could be the desires of the kind expressed in a framework for auditing. The Task Force acknowledged that such material may also 'identify and describe other procedures and actions relating to the activities of the professional accountant' that they have a 'professional responsibility to consider'. This suggests that it sets out some kind of requirement. They went on to say that it is not intended though that such guidance should impose 'a direct responsibility...to perform the identified procedures and actions' (IAASB, 2003j, §16). In other words, it is and is not a requirement. This was further confused by the suggestion of the Task Force that other procedures and actions included in the explanatory material 'should be characterized as "suggested" or "optional" procedures in order to better convey the intended nature of such guidance'. It is not required but only suggested. It is no wonder that members of the IAASB at the meeting felt the need for further clarification of the nature of explanatory guidance.

This was bound up in the debate about 'equal authority'. Respondents to the First ED recommended that the IAASB 'clarify the authority of bold type and ordinary type lettering and establish, unequivocally, that both lettering have equal authority (similar to the statement adopted by the IASB)' (IAASB, 2003a, §5). This was given weight by the suggestion of the American Institute of Certified Public Accountants (AICPA) that a statement that paragraphs in bold and plain type 'have equal authority' of the kind that appears in the Preface to International Financial Reporting Standards should be included in the Preface to auditing standards (IAASB, 2003c, p. 451). The issue of 'equal authority' was interpreted by some respondents, such as IOSCO, as an issue of the mandatoriness, or otherwise, of standards (IAASB, 2003c, p. 453). This makes sense if such statements are interpreted as requirements but not if they are 'descriptive'. Doubts about the meaning of 'equal authority' were raised. At the December 2003 meeting of the IAASB, the Task Force proposed " "equal authority" means that there is no difference in the level of authority between the different paragraphs within a standard' (IAASB, 2003i, p. 9).

A number of restructuring options were put forward by the Task Force in their Discussion Paper in order to distinguish requirements from explanatory material (IAASB, 2004b, pp. 11-12). The Consultation Paper in the First ED stated that professional requirements 'are to be understood and applied in the context of the explanatory and other material that provides guidance for their application. Professional accountants have a responsibility to consider the entire text of an International Standard in carrying out their work' (IAASB, 2004a, §2). The view was reiterated that explanatory material was 'intended to be descriptive rather than imperative' and 'explains the objective ... and provides additional information for the professional accountant to consider in exercising professional judgment in performing the engagement' (IAASB, 2004a, §7). The Explanatory Memorandum explains that the IAASB did consider the option of stating that 'the entire text of an International Standard has "equal authority", this term to be explained as meaning that there is no difference in the level of authority between the different paragraphs within an International Standard'. However, they decided that the same effect could be achieved without using such an expression (IAASB, 2004a, p. 9). At the Rome meeting of the IAASB in 2005, members agreed with the Task Force recommendation to restructure ISAs into three sections: objectives, requirements and essential explanatory material and application guidance. The acceptance by the IAASB of this restructuring was conditional upon requiring the auditor to comply with the requirements and to consider the application material so that it was not overlooked (IAASB, 2005b, p. 16). This idea eventually finds its way into ISA 200 which says that the auditor shall have an understanding of the entire text of an ISA, including its application and other explanatory material, to understand its objectives and to apply its requirements properly' (IAASB, 2009a, §19).

What is missing in these considerations is a clear statement about the nature of explanatory guidance. One way of understanding sentences 
that express such material is to take them as giving an explanation of the meaning of expressions contained in the prescription of requirements. These can be understood as rules for the meaning of expressions (Baker \& Hacker, 1980, p. 36). If so, they are in the nature of prescriptions, but they are not prescriptions about what to do in an auditing situation but about how to understand expressions in sentences that say what is to be done. Interpreted in this way the 'guidance' makes it clear what is required to be done by prescriptions of procedures. It is important to note that the rule formulation, the words used to express a rule, and the rules of meaning together determine the rule. This is really the idea that lies behind the idea of 'equal authority'. The need for such 'guidance' would be obvious if the prescription could not be understood at all without guidance of this kind. An example would be a prescription that said 'the auditor should perform RAPs'. This might be understood in various ways by auditors and probably is not to be understood as requiring the auditor to sing in a particular way. Explanatory guidance might accompany such a prescription. This could be something like 'RAPs are risk assessment procedures'. Further guidance would then explain what is meant by 'risk assessment procedures'. It would then be clear what was to be done.

Given such guidance, one requirement can be derived from another. If there is a requirement to undertake risk assessment procedures then, given an explanation of the meaning of 'risk assessment procedures', further requirements to do X, Y and Z can be derived. This derivation could be made by the standard setter who would then state these derived requirements in an auditing standard. If this was done then the number of requirements in an auditing standard would increase. If a 'rules-based' system is interpreted as one that includes a large number of requirements, then standard setters who derive such requirements may be thought to be operating such a system. If the general rule, such as 'the auditor should perform RAPs', is issued without any guidance on the meaning of 'RAPs' then this might be interpreted as 'principles-only'. Standards of this kind also provide 'insufficient guidance to make the standards reliably operational'. This might be interpreted as a standard that did not include explanatory material that explained the meaning of expressions in standards. Providing voluminous quantities of such guidance might be interpreted as providing an interpretation of a general rule like 'the auditor should perform RAPs' that, in effect, requires the derivation of a large number of detailed rules. Whether the standard setter derives the rules or leaves it to the professional guided by explanatory guidance the result might be 'complex' or 'rules-based' standards of the kind that the IAASB accepted as problematic at the outset of the Project.

A middle way is to provide the general rule but with only some explanatory material and then leave it to the professional accountant to decide on the meaning of expressions in the rule formulation. In effect, the professional accountant would be using their judgement to determine what the rule should be. This is a different kind of professional judgement than that exercised in deciding whether to undertake procedures not required in ISAs or not to override a rule. It is a decision about a course of action, but the action in question is the determination of a rule. As such they are, in effect, acting as standard setters. Professionals use the objectives or desires of auditing to decide on the meanings or interpretation of expressions in rule formulations where there is discretion to make such decisions. The combination of relatively small amounts of implementation guidance along with the need to consider objectives of standards to decide on the meaning of expressions in a rule formulation explains why these are taken as characteristics of a 'principles-based' or 'objectives-based' standard. The thought that lies behind the idea that explanatory material should have 'equal authority' is the idea that the prescription of the meaning of expressions in rule formulations is equally mandatory as are the prescriptions of procedures in auditing standards. They are prescriptions that say how the professional accountant must understand an expression in a prescription of what is to be done. This determines what the requirement expressed in a rule entails, that is, what further requirements follow from the rule.

Thus far the ideas of overall objectives, requirements in ISAs and explanatory material have been explained. What about the idea that there are objectives in ISAs?

\section{THE IDEA OF AN OBJECTIVE IN AN ISA}

During the evolution of the Clarity Project there was a worry that requirements were not adequately 
differentiated from objectives in ISAs. Respondents to the Second ED thought that 'the draft objectives take the form more of a summary of "highlevel [mandatory] requirements" (or a mixture of high-level outcomes and "high-level requirements") than true objectives, and often appear to be "process" driven' (IAASB, 2006c, p. 8). The IAASB accepted that 'objectives should reflect the outcome that the ISA is directing the auditor to achieve, and that objectives that are procedural in form may diminish the benefits of specifying objectives and blur the distinction between them and the requirements' (IAASB, 2006a, \$19). In the December 2006 version of the Amended Preface, the IAASB 'considered that setting objectives at too high a level may make them ineffective. Accordingly, the IAASB is of the view that the objectives need to be specific enough to assist the auditor in: determining what is to be accomplished; understanding how the objectives and requirements relate; deciding what more, if anything, needs to be done, and evaluating whether they have been met' (IAASB, 2006a, §19). The IAASB agreed that the general form of objectives in ISAs should be 'to [achieve outcome] through some means (if necessary or helpful to specify the means in the objective)'. That is, the objective is always the end, but it may sometimes be necessary to state the means to make the objective more effective' (IAASB, 2006a, \$20).

The 'general form of objectives' suggests that an objective in an ISA expresses both a desire to bring about a certain event through some actions of the auditor and a requirement that prescribes actions that will bring about a certain event. It appears like the command to do something to achieve a certain end. As suggested above, the problem with that kind of command and with objectives in ISAs is that it is unclear what the auditor has to do. Are they simply to perform the action required? If so then the reason for stating the desire that is meant to be performed by the action is unclear.

The failure to clarify the nature of objectives can be illustrated by considering some examples of objectives in ISAs. The objective in ISA 230 states that the objective of the auditor is to prepare documentation that provides: (a) A sufficient and appropriate record of the basis for the auditor's report; and (b) Evidence that the audit was planned and performed in accordance with ISAs and applicable legal and regulatory requirements' (IAASB, 2009b, §5). This looks like a straightforward prescription of an action. Auditors are required to 'prepare documentation' of a certain sort. It might be made to conform to the 'general form of an objective' by re-describing the requirement as 'auditors are required to do something to bring it about that a sufficient and appropriate record ... is provided'. This event or state of affairs of having such a record is the outcome. The means or what has to be done to bring about this state of affairs is to 'prepare documentation'. This is rather contrived though, for the documentation that is to be prepared is not just any documentation but that which constitutes a 'sufficient and appropriate record'. It would be more straightforward to say that what is required is that auditors produce a record setting out the basis of the auditor's report and a certain kind of evidence. The objective is simply a requirement for the auditor to do something.

The objective in ISA 315 states that 'the objective of the auditor is to identify and assess the risks of material misstatement, whether due to fraud or error, at the financial statement and assertion levels, through understanding the entity and its environment, including the entity's internal control, thereby providing a basis for designing and implementing responses to the assessed risk of material misstatement' (IAASB, 2009d, §3). This might be re-described in a way that seems to conform to the general form of objectives in ISAs. The outcome is the provision of a basis for designing and implementing responses to assessed risk. The means is the identification and assessment of risk. The action of identifying and assessing risks does result in something that provides the means to achieve the outcome of providing a basis for designing and implementing responses to assessed risk. All this really means though is that auditors have to do something that brings about a certain result before they can do something else that makes use of what has been brought about. This is no different than doing something in a recipe that has to be done before something else is done. One has to put the kettle on before one can pour boiling water into the teapot. In other words, one has to do something to bring it about that there is boiling water before one can do something to bring about that there is boiling water in the teapot. This might simply be re-described as performing two actions, one of which has to precede the other. One has to identify and assess risks before one can respond to the risks identified. The objective merely sets out two requirements in a recipe. 
The objective stated in ISA 300 is 'the objective of the auditor is to plan the audit so that it will be performed in an effective manner' (IAASB, 2009c, §3). This might conform to the 'means/outcome' form of an objective. Planning the audit is the means to performing it effectively. The latter is an outcome. What they have to do is to plan the audit. This is the means. Alternatively, it may be that this objective is simply a requirement for auditors to perform an effective audit. What this means needs to be explained. It may be that it achieves the fulfilment of desires of the kind expressed in ISA 200. It may also refer to doing so in an efficient manner. If the latter is the case then this might be interpreted as undertaking procedures in a 'cost-effective' or 'cost-beneficial' manner. This seems to introduce some other desires that underlie the requirement to plan an audit. This kind of desire has sometimes been suggested as governing auditing procedures (Porter, 1993, p. 62; FEE, 2003, pp. 16-17). A desire of this kind does not appear in ISA 200. If it is actually part of the reason why standard setters promulgate standards requiring auditors to undertake procedures then these desires are the kind of thing that a conceptual framework would consider. The decision to abandon that part of the Clarity Project which would have looked at these issues suggests that a grasp of the reasons for promulgating standards containing requirements included in ISA 200 are not complete (Dennis, 2010, p. 141). Including the idea of 'effectiveness' in ISA 300 might be a way of rectifying this omission. If so, then it expresses a desire that may govern the promulgation of an auditing standard.

If the objectives in an ISA are requirements then the auditor must bring about certain events that together, in a causal net, will achieve the overall objective of auditing. Auditing standards might be said to be 'objectives-based' if they require auditors to do something to bring about certain events in this net. During the evolution of the Clarity Project there seems to have been a shift from the idea that a standard is 'objectives-based' if it is promulgated for reasons expressed in overall objectives of auditing, to the idea that it is 'objectives-based' if it expresses an objective for auditors to bring about certain events. This shift enabled the IAASB to maintain that standards were 'objectives-based' in the face of the abandonment of the project to express objectives in a framework for such objectives are simply prescriptions of procedures. It was in this sense that the FEE suggested that 'objectives' should be stated at each stage of the audit. This only means that requirements to bring about certain events should be prescribed for the auditor.

The ambiguity as to whether an objective is a desire or a requirement is understandable given the nature of practical reasoning. If a standard setter wants to fulfil a desire and believes that if auditors undertake a certain procedure then the desire will be fulfilled then they may conclude with a desire that auditors undertake the procedure. If this is the case then they may promulgate a requirement in a standard that auditors undertake the procedure. If the desire is to obtain reasonable assurance that the financial statements are free from material misstatement and it is believed that this can be achieved by the auditor identifying and assessing risks of misstatement, then the standard setter may conclude that they want auditors to identify and assess risks of misstatement. This desire might be described as an objective, understood as a desire, of the standard setter. It can be expressed by 'I want auditors to identify and assess risks of misstatement'. The requirement that is promulgated in a standard is for auditors to identify and assess risks of misstatement. This can be expressed by 'Auditors are required to identify and assess risks of misstatement'. What is wanted and what is required are expressed by the same phrase 'to identify and assess risks of misstatement'. It is not surprising that the difference between a desire and a requirement might not be understood and that an objective might at one time be taken to express a desire and at another a requirement. The nature of the objectives in ISAs is, as a result, unclear and the statement of an objective in an ISA appears to have different roles.

\section{CONCLUSIONS}

The Clarity Project was really two projects rolled into one. These correspond with the two senses of 'principles-based' standards. One strand of the Project sought to formulate 'fundamental principles of auditing' and identify the reasons for standard setters promulgating auditing standards. The IAASB attempted to kill off this part of the Project but its ghost came back to haunt them in the redrafting of ISA 200. 'Principles' that should appear in a conceptual framework for auditing resurfaced in auditing standards and the distinction between something that sets out 
requirements for procedures that auditors are to follow and something that expresses the reasons why these requirements are prescribed was blurred. The idea of a conceptual framework, or 'fundamental principles' for auditing, was not clarified. The objective of the other strand was to formulate auditing standards that have certain qualities, namely being 'objectives-based'. Again, the outcomes were not clear because the idea of an objective and of being 'objectives-based' was not clarified.

The paper has made a start in trying to clarify issues on both sides of the Clarity Project. It suggests that a framework for standards is one that sets out what is wanted from the activity of auditing. These desires for ends that are to be achieved through auditing are used by standard setters in practical reasoning to a desire to promulgate auditing standards. If these are followed by auditors the desires will be fulfilled. Practical reasoning is explained and the nature of the reasons for promulgating auditing standards clarified. The paper also examines the idea of 'objectives-based' standards. The idea of 'objectives' is ambiguous and might mean an end or outcome desired or a requirement for auditors to perform some procedure. Objectives in ISAs might be either.

The paper also clarifies the idea of a requirement. A requirement is a rule that prescribes that auditors undertake certain procedures. The nature of rules and of the different kinds of rules that might be promulgated in auditing standards is discussed. The IAASB is not clear on the kind of rules that it wishes to prescribe. It is not clear whether they conceive rules as 'rules of thumb' or rules on the 'practice' conception, for rules in ISAs are sometimes of one kind of rule and sometimes of the other kind. The reasons for wanting to promulgate rules of either kind are explored. This is related to the idea that following such rules is a necessary or sufficient condition of achieving the desires that are expressed in the overall objectives of auditing. The IAASB's idea that standards are 'interrelated' is explained in terms of 'causal nets'. Performing auditing procedures results in the occurrence of events or states of affairs that together achieve the overall desires for auditing as part of a 'causal net'. Different causal nets might achieve the same result and this has important implications for the necessity of auditing procedures. This has implications for the kind of language used to express these requirements. Standard setters need to consider both necessary and sufficient conditions when promulgating auditing standards. This picture of standards and standard setting was incompletely grasped by the IAASB and its constituents in the evolution of the Clarity Project. It is suggested that the IAASB's desire for 'principles-based' auditing standards was misdirected by an inadequate examination of the meaning of the term 'principles-based'.

It is interesting to note that the revisions to ISAs that were eventually finalized after the completion of the Clarity Project were already 'in progress or nearly complete when the Clarity Project began' (IAASB, 2008c, p. 1). They were not released until they could be redrafted in accordance with the new Clarity conventions. Although the IAASB maintain that this revision results in 'new requirements that aim to improve practice' (IAASB, 2008c, p. 1), the difference made by the Project is questionable. The clarification of auditing standards did not proceed from a fundamental consideration of the nature of auditing standards, the concepts that are used to characterize and describe them and the process of promulgating them. Instead certain concepts were used to re-package standards that had already been determined. If this is the case then it is not surprising that the results of the Clarity Project appear to have wide acceptance. If little of significance was changed as a result of the Project then there was little to object to. It was a missed opportunity to undertake a more fundamental review of the nature of auditing standards and of the concepts that describe and characterize them.

This paper has made a start in a more fundamental examination of auditing standards. If the IAASB had undertaken adequate conceptual enquiries the evolution of the Project might not have been so convoluted and the outcomes clearer. The Project began with the objective of bringing clarity to auditing standards. This cannot be achieved without an examination of the concepts that underpin the Project. Although these concepts 'directed the interest' of the IAASB and its constituents, the lack of understanding of these concepts and their ambiguity may have actually misdirected it. After all, clarity begins at home!

\section{ACKNOWLEDGEMENTS}

I am grateful to Wolfgang Böhm of the Institut der Wirtschaftsprüfer for his helpful comments on an earlier version of this paper. I would also like to 
thank Steven Leonard of the staff of the Auditing Practices Board, Dennis van Liempd, and the editor and two anonymous reviewers of the International Journal of Auditing for comments that were useful in developing the paper.

\section{REFERENCES}

Accounting Standards Board (1999), Statement of Principles for Financial Reporting, London: ICAEW.

Anscombe, G. E. M. (1957), Intention, Oxford: Basil Blackwell.

Archer, S. (1993), 'On the methodology of constructing a conceptual framework for financial accounting, in M. Mumford and K. Peasnell (eds), Philosophical Perspectives on Accounting, London: Routledge.

Baker, G. \& Hacker, P. (1980), Wittgenstein: Meaning and Understanding, Oxford: Blackwell.

Baker, G. \& Hacker, P. (1985), Wittgenstein: Rules, Grammar and Necessity, Oxford: Blackwell.

Dennis, I. (2006), 'Here we go again...', Comment Letter 50 on the IASB Discussion Paper 'Preliminary Views on an Improved Conceptual Framework for Financial Reporting - The Objective of Financial Reporting and Qualitative Characteristics of Decisionuseful Financial Reporting Information', Available from http:/ / www.iasb.org/NR/rdonlyres/2D4D6717557F-47AA-8BB2-A22E6FCCADF0/0/CL50.pdf (accessed 29 October 2009).

Dennis, I. (2008), 'A conceptual enquiry into the concept of a "principles-based" accounting standard', British Accounting Review, Vol. 40, No. 3, pp. 260-71.

Dennis, I. (2010), 'What do you expect? A reconfiguration of the audit expectations gap', International Journal of Auditing, Vol. 14, No. 2, pp. 130-46.

Dopuch, N. \& Sunder, S. (1980), 'FASB's statements on objectives and elements of financial accounting: a review', Accounting Review, Vol. 55, No. 1, pp. 1-21.

Financial Accounting Standards Board (2002), Proposal: Principles-Based Approach to US Standard Setting, Norwalk, CT: FASB.

Financial Accounting Standards Board/International Accounting Standards Board (2005), Revisiting the Concepts: A New Conceptual Framework Project, Norwalk, CT: FASB.

FEE (2003), Issues Paper Principles of Assurance: Fundamental theoretical issues with respect to assurance in assurance engagements, Bruxelles: Fédération des Experts Comptables Européens.

Goldman, A. I. (1970), A Theory of Human Action, Princeton, NJ: Princeton University Press.

Hacker, P. M. S. (1996), Wittgenstein: Mind and Will, Part I: Essays, Oxford: Blackwell.

Hines, R. (1989), 'Financial accounting knowledge, conceptual framework projects and the social construction of the accounting profession', Accounting, Auditing and Accountability Journal, Vol. 2, No. 2, pp. 72-92.

IAASB (2003a), Agenda Item 3-D - Operations Policy No 1 - Issues Paper, Available from: http:// www.ifac.org/IAASB/Meeting-BGPapers.php? $\mathrm{MID}=0014 \&$ ViewCat $=0029$ (accessed 21 October 2009).

IAASB (2003b), Agenda Item 3-E - Proposed Revised Operations Policy No 1, Available from: http:// www.ifac.org/IAASB /

Meeting-BGPapers.php?MID=0014\&ViewCat $=0029$ (accessed 21 October 2009).

IAASB (2003c), Agenda Item 3-F - Operations Policy No 1 -Comments Received and Proposed Disposition, Available from: http://www.ifac.org/IAASB/ Meeting-BGPapers.php?MID=0014\&ViewCat $=0029$ (accessed 20 October 2009).

IAASB (2003d), New York Meeting Minutes, Available from: http:/ / www.ifac.org/IAASB/MeetingMinutes.php?MID=0003 (accessed 20 October 2009).

IAASB (2003e), Agenda Item 5-A - Improving the Clarity of IAASB Standards, Available from: http:/ / www.ifac.org/IAASB/Meeting-BGPapers.php ?MID=0003\&ViewCat=0044 (accessed 20 October 2009).

IAASB (2003f), Agenda Item 6-B - Proposed Revised Preface, Available from: http://www.ifac.org/ IAASB / Meeting-BGPapers.php?MID=0003\&View Cat $=0045$ (accessed 20 October 2009).

IAASB (2003g), Tokyo Meeting Minutes, Available from: http:/ / www.ifac.org/IAASB/Meeting-Minutes. php?MID=0004 (accessed 20 October 2009).

IAASB (2003h), Agenda Item 10-A - Issues Paper, Available from: http://www.ifac.org/IAASB/ Meeting-BGPapers.php?MID=0004\&ViewCat $=0069$ (accessed 20 October 2009).

IAASB (2003i), Berlin Meeting Minutes, Available from: http:/ / www.ifac.org/IAASB/Meeting-Minutes. php?MID=0013 (accessed 20 October 2009).

IAASB (2003j), Agenda Item 7-A - Clarity - Proposed Policy Statement, Available from: http://www. ifac.org/IAASB/Meeting-BGPapers.php?MID= 0013\&ViewCat $=0077$ (accessed 20 October 2009).

IAASB (2004a), Exposure Draft Proposed Policy Statement, 'Clarifying Professional Requirements in International Standards Issued by the IAASB' Consultation Paper Improving the Clarity and Structure of IAASB Standards and Related Considerations for Practice Statements, New York: IFAC.

IAASB (2004b), Agenda Item 2-A-Discussion Paper Improving the Clarity of IAASB Standards, Available from: http://www.ifac.org/IAASB/MeetingBGPapers.php?MID $=0017 \&$ ViewCat $=0128$ (accessed 20 October 2009).

IAASB (2005a), Proposed Amendments to the Preface to the International Standards on Quality Control, Auditing, Assurance and Related Services, New York: IFAC. 
IAASB (2005b), Rome Meeting Minutes, Available from: http://www.ifac.org/IAASB/MeetingMinutes.php?MID=0038 (accessed 20 October 2009).

IAASB (2005c), Agenda Item 9-A - Rome Meeting Issues Paper and Proposal, Available from: http://www. ifac.org/IAASB/Meeting-BGPapers.php?MID= 0038\&ViewCat $=0288$ (accessed 20 October 2009).

IAASB (2005d), Agenda Item 9-D - (Clarity) Respondent's Comments, Available from: http:// www.ifac.org/IAASB/Meeting-BGPapers.php? $\mathrm{MID}=0038 \&$ ViewCat $=0288$ (accessed 20 October 2009).

IAASB (2005e), New York Meeting Minutes, Available from: http://www.ifac.org/IAASB/MeetingMinutes.php?MID=0039 (accessed 20 October 2009).

IAASB (2005f), Agenda Item 4- $A$ - Discussion Paper, Available from: http://www.ifac.org/IAASB/ Meeting-BGPapers.php?MID=0039\&ViewCat $=0354$ (accessed 20 October 2009).

IAASB (2006a), Basis for Conclusions: Clarity, New York: IFAC.

IAASB (2006b), Preface to the International Standards on Quality Control, Auditing, Review, Other Assurance and Related Services, New York: IFAC.

IAASB (2006c), Agenda Item 6-A - Clarity of IAASB standards - Issues Paper, Available from: http:// www.ifac.org/IAASB/

Meeting-BGPapers.php?MID=0065\&ViewCat=0519 (accessed 21 October 2009).

IAASB (2006d), Brussels Meeting Minutes, Available from: http://www.ifac.org/IAASB/MeetingMinutes.php?MID=0066 (accessed 21 October 2009).

IAASB (2006e), Montreal Meeting Minutes, Available from: http://www.ifac.org/IAASB/MeetingMinutes.php?MID=0076 (accessed 21 October 2009).

IAASB (2006f), Agenda Item 2A - Montreal Meeting Issues Paper, Available from: http:/ / www.ifac.org/ IAASB /Meeting-BGPapers.php?MID=0076\&View Cat $=0573$ (accessed 21 October 2009).

IAASB (2007), International Auditing and Assurance Standards Board: a brief history of its development and progress, Available from: http://web.ifac.org/ download/IAASB_Brief_History.pdf (accessed 17 May 2010).

IAASB (2008a), Basis for Conclusions: ISA 200 (Revised and Redrafted), Overall Objectives of the Independent Auditor and the Conduct of an Audit in Accordance with International Standards on Auditing, New York: IFAC.

IAASB (2008b), New York Meeting Minutes, Available from: http:/ / www.ifac.org/IAASB/MeetingMinutes.php?MID=0141 (accessed 21 October 2009).

IAASB (2008c), IAASB Clarity Project Update, Available from: http://web.ifac.org/download/IAASB_ Clarity_10-08.pdf (accessed 14 October 2009).

IAASB (2009a), ISA 200, New York: IFAC.

IAASB (2009b), ISA 230, New York: IFAC.

IAASB (2009c), ISA 300, New York: IFAC.

IAASB (2009d), ISA 315, New York: IFAC.

IAASB (2010), Home Page, Available from: http:// www.ifac.org/IAASB/index.php (accessed 17 May 2010).

ICAS (2006), Principles Not Rules. A Question of Judgement, ICAS: Edinburgh.

Lemmon, E. J. (1965), Beginning Logic, London: Nelson University Paperbacks.

Loft, A., Humphrey, C. \& Turley, S. (2006), 'In pursuit of global regulation: changing governance and accountability structures at the International Federation of Accountants (IFAC)', Accounting, Auditing \& Accountability Journal, Vol. 19, No. 3, pp. $428-51$.

Mattessich, R. (1995), 'Conditional-normative accounting methodology: incorporating value judgements and means-end relations of an applied science', Accounting, Organizations and Society, Vol. 20, No. 4, pp. 259-84.

Porter, B. (1993), 'An empirical study of the audit expectation-performance gap', Accounting and Business Research, Vol. 24, No. 93, pp. 49-69.

Rawls, J. (1955), 'Two concepts of rules', Philosophical Review, 64, reprinted in Theories of Ethics (1967), edited by Foot, in the Oxford Readings in Philosophy series, Oxford: Oxford University Press, pp. 144-70.

Schipper, K. (2003), 'Principles-based accounting standards', Accounting Horizons, Vol. 17, No. 1, pp. 61-72.

SEC (2003), Study pursuant to Section 108 (d) of the Sarbanes-Oxley Act of 2002 on the Adoption by the United States Financial Reporting System of a principles-based accounting system.

Twining, W. \& Miers, D. (1976), How to do Things with Rules, London: Weidenfeld and Nicolson.

Van Fraassen, B. C. (1980), The Scientific Image, Oxford: Clarendon Press.

West, B. (2003), Professionalism and Accounting Rules, London: Routledge. 